University of Nebraska - Lincoln

DigitalCommons@University of Nebraska - Lincoln

Faculty Publications, Department of Psychology

Psychology, Department of

January 2007

\title{
Depression vulnerability within smoking research: How accurate are one-item screening items?
}

Dennis E. McChargue

University of Nebraska-Lincoln, dmcchargue2@unl.edu

Jessica Werth Cook

VA Puget Sound Health Care System-Seattle Division, Seattle, United States

Follow this and additional works at: https://digitalcommons.unl.edu/psychfacpub

Part of the Psychiatry and Psychology Commons

McChargue, Dennis E. and Werth Cook, Jessica, "Depression vulnerability within smoking research: How accurate are one-item screening items?" (2007). Faculty Publications, Department of Psychology. 269. https://digitalcommons.unl.edu/psychfacpub/269

This Article is brought to you for free and open access by the Psychology, Department of at DigitalCommons@University of Nebraska - Lincoln. It has been accepted for inclusion in Faculty Publications, Department of Psychology by an authorized administrator of DigitalCommons@University of Nebraska - Lincoln. 


\title{
Short Communication
}

\section{Depression vulnerability within smoking research: How accurate are one-item screening items?}

\author{
Dennis E. McChargue ${ }^{\mathrm{a}, \mathrm{b}, *}$, Jessica Werth Cook $^{\mathrm{c}}$ \\ ${ }^{a}$ University of Nebraska-Lincoln, 238 Burnett Hall, P.O. Box 880308, Lincoln, NE 68588-0308, United States \\ ${ }^{\mathrm{b}}$ University of Illinois at Chicago, Chicago, United States \\ ${ }^{\mathrm{C}}$ VA Puget Sound Health Care System-Seattle Division, Seattle, United States
}

\begin{abstract}
Epidemiological and large scale treatment studies within smoking research have utilized many one-item screening items to examine the influence of current depressive symptoms on smoking behavior and quitting. Little is known about that concurrent validity of screening items that may reflect depression vulnerability independent of current symptoms. The present paper evaluated the concurrent validity of two one-item screening items that were essential for diagnosing past episodes of major depression. Screening questions were administered to seventyseven nicotine dependent participants via a telephone screening interview. Smokers then returned to the laboratory for a comprehensive structured assessment of depressive vulnerability. Vulnerability measures were cliniciandiagnosed history of major depressive disorder and other self-reported depressive vulnerability factors. Telephone screening items accurately classified a clinician-diagnosed history of major depression, and predicted the number of recurrent depressive episodes, self-reported rumination, and self-reported depression-proneness (all $p<0.05$ ). Results support the utility of one-item screening questions as a "proxy" of a depressive vulnerability for smoking treatment studies that are not designed for comprehensive assessment procedures.
\end{abstract}

(C) 2006 Elsevier Ltd. All rights reserved.

Keywords: Cigarette smoking; Assessment; Depression

\footnotetext{
* Corresponding author. University of Nebraska-Lincoln, 238 Burnett Hall, P.O. Box 880308, Lincoln, NE 68588-0308, United States. Tel.: +1 402472 3197; fax: +1 4024724637 .

E-mail address: dmcchargue2@unl.edu (D.E. McChargue).
} 


\section{Introduction}

Relatively asymptomatic smokers with a history of major depressive disorder (MDD Hx) have been a targeted subpopulation within smoking research. Structured interviews to assess depressive vulnerability are traditionally employed within such studies (e.g., Hitsman, Borrelli, McChargue, Spring, \& Niaura, 2003). With few exceptions (Niaura et al., 1999), one-item depression scales have yet to potentially approximate (proxy) MDD vulnerability beyond current depressive symptoms (e.g., Hughes, 1992). The purpose of the present study was to examine the concurrent validity of two one-item "proxies" of MDD vulnerability among euthymic smokers.

MDD vulnerability was defined as consisting of a cluster of stable, endogenous and latent characteristics (Ingram \& Price, 2001), which include clinician-diagnosed past MDD episodes, selfreported depression proneness, trait-anhedonia, and ruminative coping styles. Such endogenous and stable factors have been reflective of either a latent response to MDD episodes or predictive of future MDD exacerbations (Just \& Alloy, 1997; Lewinsohn, Rohde, Seeley, Klein, \& Gotlib, 2000; Loas, 1996). We hypothesized that one-item endorsement would be associated with greater numbers of cliniciandiagnosed MDD Hx, higher self-reported depressive proneness scores, trait-anhedonia, and ruminative coping styles among a sample of smokers.

\section{Methods}

\subsection{Participants}

Seventy-seven smokers (34.6\% male) participated in the present study. On average, participants were 40.65 years old (S.D. = 10.39). The sample was 65.1\% African American, 1.3\% Asian, 28.2\% Caucasian, $3.8 \%$ Latino, and $1.3 \%$ multicultural. Forty percent received a high school education or less, $49 \%$ reported some college or trade school, 6.5\% reported a Bachelor's degree, and 3.9\% reported obtaining a graduate degree or higher. On average, the participants reported smoking 20.32 (S.D. =6.67) cigarettes per day, smoked for the past 22.16years (S.D. $=10.59)$, and reported an average dependence score of 4 (S.D. = 1.37) as measured by the Fagerström Test for Nicotine Dependence (Heatherton, Kozlowski, Frecker, \& Fagerström, 1991). Participants were excluded if they had a medically unstable condition or had current MDD or any other axis I disorder other than nicotine dependence. Women with late gluteal phase disorder or severe premenstrual disturbance were also excluded.

\subsection{Measures}

\subsubsection{One-item screening questions}

To assess for the likelihood of a MDD Hx, participants were asked via telephone: (1) Have you ever been down or depressed most of the day nearly everyday for 2 weeks or more (depression screen), and (2) Have you ever lost interest or pleasure in things you typically enjoy most of the day nearly everyday for 2 weeks or more (anhedonia screen). These items were chosen for the screen because the structure of such questions may increase our psychometric specificity by referencing a 2-week period of consecutive days of depression or loss of pleasure at any time in the persons life as opposed to the traditional momentary and situationally specific assessment of current depressive symptoms. Clinicians that conducted the 


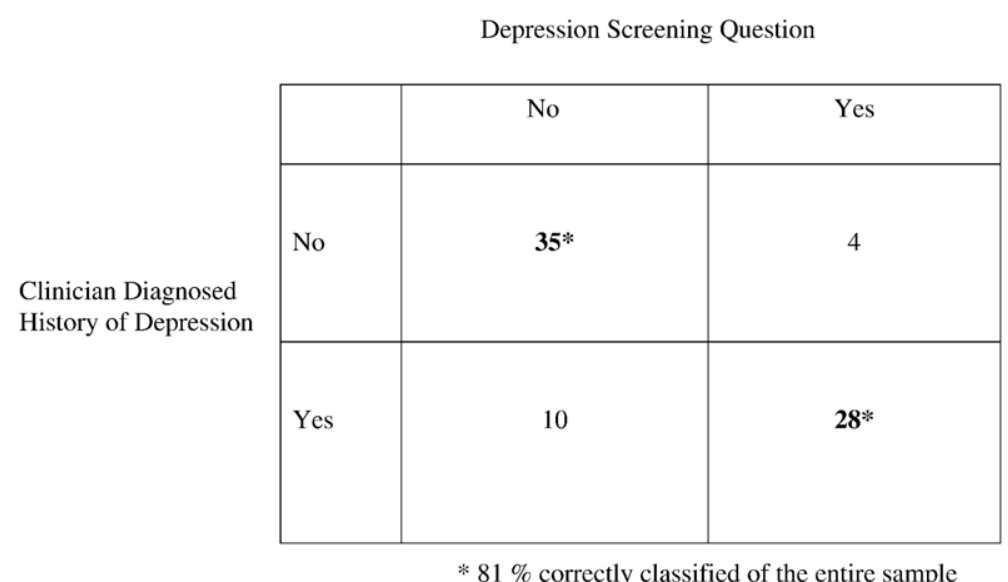

Fig. 1. Classification table for chi-square analysis examining whether the one-item depression screening question predicted clinician diagnosed history of depression.

structured interviews were blind to the participants' endorsement status of the telephone screening questions.

\subsubsection{MDD vulnerability measures}

The Structured Clinical Interview for DSM-IV-Nonpatient version (SCID-NP; Spitzer, Williams, Gibbon, \& First, 1992) was administered by a trained clinician to rule out current axis I disorders other than nicotine dependence and to identify the number of past MDD episodes. The Fawcett-Clark Pleasure Scale (FCPS; Fawcett, Clark, Scheftner, \& Gibbons, 1983) measured trait anhedonia. The Response Style Questionnaire (RSQ; Nolen-Hoeksema, 1991) was used to measure dispositional ruminative responses to dysphoric mood. Lastly, the Depression Proneness Inventory (DPI; Zemore, 1983) was used to assess proneness to depression.

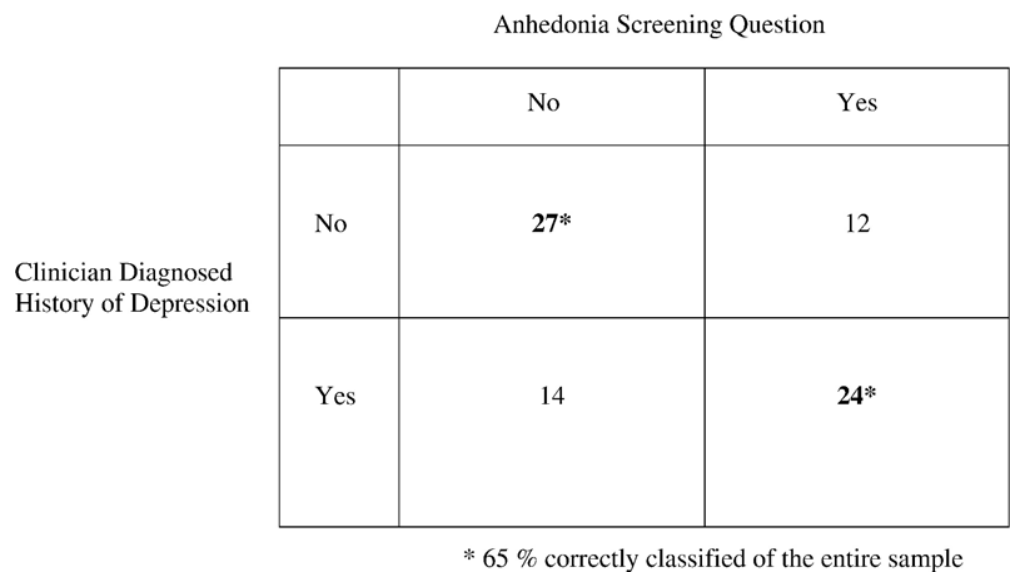

Fig. 2. Classification table for chi-square analysis examining whether the one-item anhedonia screening question predicted clinician diagnosed history of depression. 
Table 1

Intercorrelations among predictor and criterion variables $(N=78)$

\begin{tabular}{|c|c|c|c|c|c|c|c|c|c|c|}
\hline & 1 & 2 & 3 & 4 & 5 & 6 & 7 & 8 & 9 & 10 \\
\hline 1. Depression screen item & - & & & & & & & & & \\
\hline 2. Anhedonia screen item & $0.58 * *$ & - & & & & & & & & \\
\hline 3. Gender & 0.02 & -0.11 & - & & & & & & & \\
\hline 4. SCID history of depression & $0.64 * *$ & $0.33 * *$ & 0.12 & - & & & & & & \\
\hline 5. Number depressive episodes & $0.48 * *$ & $0.24 *$ & 0.09 & $0.63 * *$ & - & & & & & \\
\hline 6. Rumination & $0.40 * *$ & $0.41 * *$ & -0.07 & $0.41^{* *}$ & $0.45 * *$ & - & & & & \\
\hline 7. Depression proneness & $0.42 * *$ & $0.44 * *$ & 0.01 & $0.48 * *$ & $0.51 * *$ & $0.70 * *$ & - & & & \\
\hline 8. Anhedonia & 0.06 & 0.04 & 0.06 & -0.04 & -0.07 & -0.04 & $-0.32 * *$ & - & & \\
\hline 9. Ethnicity & $0.30 *$ & 0.01 & 0.11 & 0.10 & 0.10 & 0.05 & 0.02 & 0.12 & - & \\
\hline 10. Nicotine Dependence & $0.23 *$ & 0.13 & -0.08 & 0.14 & 0.14 & $0.31 * *$ & $0.30 * *$ & $-0.27 *$ & $-0.26^{*}$ & - \\
\hline
\end{tabular}

$* * p<0.01, * p<0.05, *$ one-tailed.

\subsection{Procedure}

\subsubsection{Screening assessment}

Assenting candidates' demographic information, smoking history, and the two one-item MDD Hx screens were gathered via a telephone interview. During a subsequent laboratory visit, a trained clinician collected informed consent and conducted the SCID-NP diagnostic interview. Scales assessing MDD vulnerability factors (FCPS, DPI, RSQ) were also disseminated.

\section{Results}

\subsection{Classification of clinician-diagnosed MDD history}

Chi-square analysis was significant between the depression screen and clinician-diagnosed MDD Hx $\left[\chi^{2}(1, N=77)=31.89, p<0.01\right]$. The depression screen correctly classified $81 \%$ of the cliniciandiagnosed history of MDD (see Fig. 1). Chi-square analysis also revealed a significant relationship between the anhedonia screen and clinician-diagnosed MDD $\operatorname{Hx}\left[\chi^{2}(1, N=77)=8.11, p<0.01\right]$, where $65 \%$ of the participants were classified correctly (see Fig. 2 and Table 1). ${ }^{1}$

\subsection{Screening items and number of MDD episodes}

After controlling for nicotine dependence and ethnicity, analysis of covariance (ANCOVA) showed a main effect for the depression screen $\left[F(1,68)=20.77, p=0.00, \eta^{2}=0.23\right]$ and the anhedonia screen $[F$ $\left.(1,68)=9.00, p=0.004, \eta^{2}=0.12\right]$ on number of past MDD episodes, and neither of these effects were moderated by gender (see Table 2).

\footnotetext{
1 As shown in Table 1, the depression and anhedonia screen questions were significantly correlated $[r=0.58, p<0.01]$, suggesting that the two items measure related but distinct constructs.
} 
Table 2

Mean responses for telephone screening items

\begin{tabular}{lccrrr}
\hline & \multicolumn{2}{c}{ Depression screen } & & \multicolumn{2}{c}{ Anhedonia screen } \\
\cline { 2 - 3 } \cline { 5 - 6 } & \multicolumn{1}{c}{ Yes } & No & Yes & No \\
\hline \# of MDD episodes & $2.47(2.55)$ & $0.44(1.07)^{* *}$ & & $1.81(2.27)$ & $0.83(1.85)^{* *}$ \\
Rumination & $34.78(7.58)$ & $28.73(6.63)^{* *}$ & & $34.50(6.81)$ & $28.39(7.11)^{* *}$ \\
DPI & $35.72(11.23)$ & $25.60\left(10.98^{* *}\right.$ & & $35.39(9.91)$ & $24.90(11.81)^{* *}$ \\
Anhedonia & $121.46(11.25)$ & $119.56(17.12)$ & & $121.00(12.96)$ & $119.78(16.55)$ \\
\hline
\end{tabular}

${ }^{* *} p<0.01,{ }^{*} p<0.05$.

\subsection{Screening items and other depressive vulnerability constructs}

ANCOVA showed a main effect for the depression screen on rumination $[F(1,72)=15.84, p=0.00$, $\left.\eta^{2}=0.19\right]$ and the depression screen question significantly interacted with gender $[F(1,72)=7.01$, $\left.p=0.01, \eta^{2}=0.09\right]$. Simple effects analyses revealed that males $[p=0.001]$ and not females $[p=0.23]$ who endorsed the depression screen reported greater rumination $[p=0.001]$ (see Fig. 3). The anhedonia screen also significantly influenced rumination $\left[F(1,72)=15.14, p=0.00, \eta^{2}=0.18\right]$, but did not interact with gender $[p=0.12]$ (see Table 2).

ANCOVA also showed that the depression screen $\left[F(1,72)=17.05, p=0.00, \eta^{2}=0.20\right]$ and the anhedonia screen $\left[F(1,72)=17.48, p=0.00, \eta^{2}=0.21\right]$ had a main effect on DPI scores, and these effects were not moderated by gender (see Table 2). Neither screening item predicted FCPS [both $p$ 's $=\mathrm{ns}$ ].

\section{Discussion}

Results show a moderate level of support for the utility of a brief, telephone assessment for MDD vulnerability. The depression screen and the anhedonia screen correctly classified a positive history of depression in $73 \%$ and $63 \%$ of study participants, respectively. Whereas, such questions more accurately classified the absence of a clinically diagnosed MDD Hx $89 \%$ of the time for the depression screen and

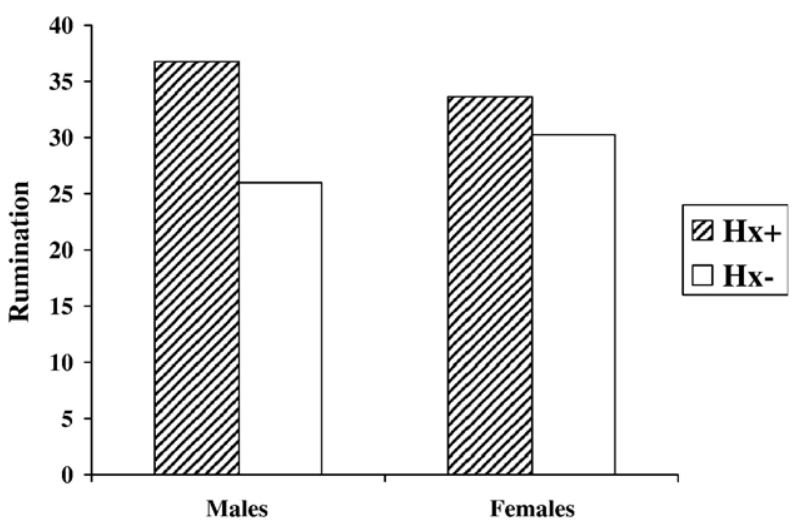

Fig. 3. Rumination among males and females with and without endorsement of depressive history. 
$69 \%$ of the time for the anhedonia screen. Such findings, in isolation, may initially suggest that the oneitem questions identify a probable MDD Hx better than $50 \%$ of the time.

Further data supporting the notion that the two screening questions reflect, to some degree, a MDD vulnerability was shown in the findings that individuals who endorsed such items reported more stable, latent, and endogenous MDD vulnerability characteristics when compared with those who did not endorse the screening items. Consistent with this premise, those who endorsed the depression and anhedonia screens had a greater number of prior episodes of clinically diagnosed MDD, reported greater levels of rumination coping styles, and had higher scores on the depression-proneness inventory. Moreover, gender did not seem to significantly influence these vulnerability characteristics with the exception of rumination. For those who endorsed the depression screen, men reported higher levels of rumination compared with females.

In sum, the present paper provides preliminary support for the use of specific one-item questions that tap into a MDD vulnerability. Although screening items did not correctly classify all participants with a MDD Hx, results support the utility of at least the depression screen when comprehensive structured interviews are not feasible. Future studies should incorporate these questions into large-scale studies in order to increase generalizability and to assess the extent to which a depressive vulnerability hinders cessation efforts. Such efforts would improve the ability to formulate more refined interpretations about the impact of a history of MDD on smoking behavior and eventual cessation.

\section{Acknowledgements}

This work was supported in part by grants: DA00467 to Dr. McChargue and DA14144 to Dr. Jessica Cook.

\section{References}

Fawcett, J., Clark, D., Scheftner, C., \& Gibbons, W. A. (1983). Assessing anhedonia in psychiatric patients. Archives of General Psychiatry, 40, 79-84.

Heatherton, T. F., Kozlowski, L. T., Frecker, R. C., \& Fagerström, K. O. (1991). The Fagerström Test for Nicotine Dependence: A revision of the Fagerström Tolerance Questionnaire. British Journal of Addiction, 86(9), 1119-1127.

Hitsman, B., Borrelli, B., McChargue, D. E., Spring, B., \& Niaura, R. (2003). Effect of history of depression on smoking cessation: A meta-analysis. Journal of Consulting and Clinical Psychology, 71(4), 657-663.

Hughes, J. R. (1992). Tobacco withdrawal in self-quitters. Journal of Consulting and Clinical Psychology, 71(4), $657-663$.

Ingram, R. E., \& Price, J. M. (2001). The role of vulnerability in understanding psychopathology. In R. E. Ingram, \& J. M. Price (Eds.), Vulnerability to Psychopathology (pp. 3-19). New York: The Guilford Press.

Just, N., \& Alloy, L. B. (1997). The response styles theory of depression: Tests and an extension of the theory. Journal of Abnormal Psychology, 106(2), 221-229.

Lewinsohn, P. M., Rohde, P., Seeley, J. R., Klein, D. N., \& Gotlib, I. H. (2000). Natural course of adolescent major depressive disorder in a community sample: Predictors of recurrence in young adults. American Journal of Psychiatry, 157(10), 1584-1591.

Loas, G. (1996). Vulnerability to depression: A model centered on anhedonia. Journal of Affective Disorders, 41, $39-53$.

Niaura, R., Britt, D. M., Borrelli, B., Shadel, W. G., Abrams, D. B., \& Goldstein, M. G. (1999). History and symptoms of depression among smokers during a self-initiated quit attempt. Nicotine and Tobacco Research, 1, 251-257.

Nolen-Hoeksema, S. (1991). Responses to depression and their effects on the duration of depressive episodes. Journal of Abnormal Psychology, 100, 569-582.

Spitzer, R. L., Williams, J. B., Gibbon, M., \& First, M. B. (1992). The Structured Clinical Interview for DSM-III-R (SCID). History, rationale, and description. Archives of General Psychiatry, 49, 624-629.

Zemore, R. (1983). Development of a self-report measure of depression-proneness. Psychological Reports, 52, $211-216$. 